\title{
ESTRUTURA GEOLÓGICA DA REGIÃO DE CAJAMAR-JORDANÉSIA, SP
}

\author{
EDGARD SANTORO*, CELSO DAL RÉ CARNEIRO**, MÍRIAN CRUXEN B. DE OLIVEIRA* \\ I JORGE HACHIRO*
}

\begin{abstract}
GEOLOGICAL SETTING OF CAJAMAR-JORDANÉSIA, SP. The geological mapping of the Cajamar-Jordanésia region (Săo Paulo State) is outlined in five lithological units belonging to the Sảo Roque Group (Upper Proterozoic). Geological, structural, and stratigraphical features support the setting. The structural trend of those units is ENE, with increasing metamorphic grade southwards. Slate and meta-arenite occur at the northern portion of the area and schists at the southern. The basal units are composed by micaschists and some porfiroblastic staurolite schists. The micaschists are in gradual contact with phyllites. Small bodies of amphibolites are found in the metapelites. The intermediate level of the lithological column is constituted by a carbonatic layer with few metapelitic inclusions. The top level is formed by metapsamites with frequent metapelitic intercalations. Three generations of folds have been recognized. The second one is impressive in any scale of analysis. It is also associated to a zonal crenulation cleavage on metapelites and responsible for the general structure outline of rocks bodies at regional scale. This paper makes reference to the soil collapses which took place in August 1986, in Cajamar town. Those collapses were related to the karstic evolution of the studied area.
\end{abstract}

\section{INTRODUÇÃO}

A ocorrência de abatimentos de solo na cidade de Cajamar (SP), em agosto de 1986, motivou a realização de estudos geológicos pelo Instituto de Pesquisas Tecnológicas do Estado de São Paulo (IPT) tanto no local do acidente (Foto 1) quanto numa área de aproximadamente 40 $\mathrm{km}^{2}$ que abrange a localidade de Jordanésia, também situada no município de Cajamar (Fig. 1). O município dista cerca de $30 \mathrm{~km}$ da capital do Estado e faz parte da Região Metropolitana da Grande São Paulo.

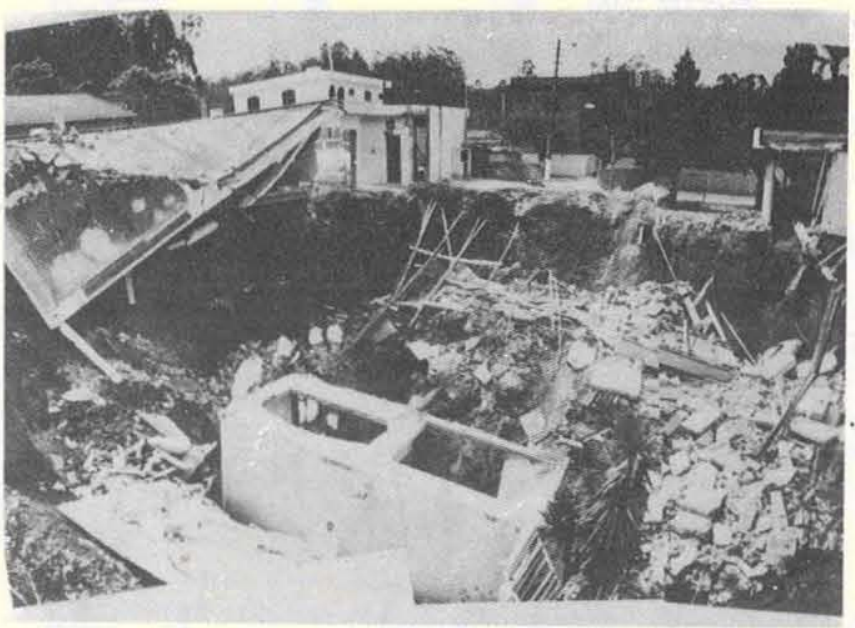

Foto 1 - Aspecto da dolina de Cajamar em outubro de 1986. Os restos da moradia, que podem ser vistos no centro da foto, fragmentaram-se completamente alguns meses depois

Os abatimentos ocorridos no solo estão vinculados à evolução de processos cársticos. Tal fenômeno foi estudado detalhadamente por Nakazawa et al. (1987) a partir de levantamentos geológicos, geomorfológicos, geotécnicos, hidrogeológicos e geofísicos (IPT 1987).

Diversos autores estudaram as rochas carbonáticas de
Cajamar. Há alguns anos, o IPT (1981a) mapeou com datalhe as pedreiras situadas a sul desta cidade, formulando a hipótese de que aí ocorreria um único nível destas rochas com caráter mais ou menos contínuo e espessura variável.

O presente trabalho analisa a geologia estrutural da área acima referida e discute a distribuição desse nível de rochas carbonáticas em termos de suas relaçôes com unidades adjacentes, continuidade, persistência e origem.



Figura 1-Localizaçâo da área estudada

Métodos de Investigação Os trabalhos de mapeamento na área foram precedidos de consulta bibliográfica e fotointerpretação preliminar, utilizando-se fotos aéreas obtidas nas escalas de 1:8.000 e 1:35.000. A seguir levantaram-se perfis orientados perpendicularmente às estruturas regionais. $\mathrm{Na}$ fase de detalhamento, cadastraram-se cerca de 400 afloramentos, adensando-se a malha de pontos visitados. O mapa geológico obtido tem densidade de informação da ordem de 10 pontos $/ \mathrm{km}^{2}$.

* Instituto de Pesquisas Tecnologicas do Estado de São Paulo S.A. (IPT), Divisão de Minas e Geologia Aplicada, Cidade Univesitária, Caixa Postal 7141 , Butantă, CEP 05508, São Paulo, SP.

** Instituto de Pesquisas Tecnológicas do Estado de São Paulo S.A. (IPT), Divisão de Minas e Geologia Aplicada e Instituto de Geociências da Unicamp. 


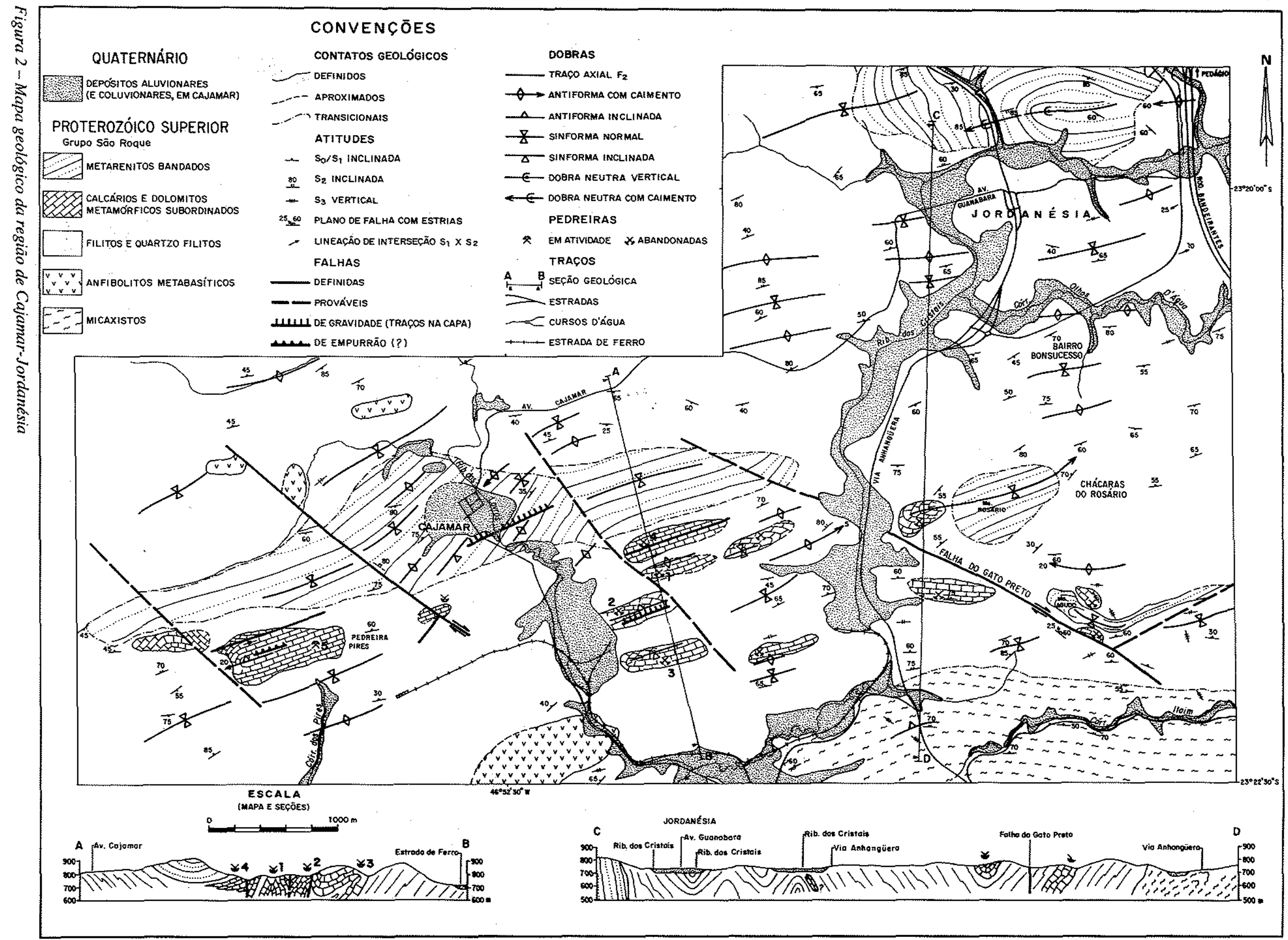


Para se conhecer a estrutura local e os fatores que condicionaram os abatimentos no solo foram executadas várias sondagens rotativas nos bairros de Lavrinhas e Vila Branca, em Cajamar. Além desses dados de subsuperff́cie, foram reinterpretadas as sondagens anteriormente executadas para pesquisa mineral nas pedreiras situadas a sul de Cajamar (IPT 1981b).

Durante os trabalhos de campo obtiveram-se medidas sistemáticas dos elementos penetrativos da trama mesoscópica das rochas, posteriormente utilizadas na análise estrutural. Nos trabalhos de reconstituição estrutual, utilizaram-se pares estereoscopicos de fotos de afloramentos com feiçōes representativas (Foto 2). A técnica favorece a recomposição de aspectos locais dos afloramentos como a natureza das juntas, dobras, falhas e continuidade das camadas.

LITOESTRATIGRAFIA Cinco unidades litológicas relacionáveis ao Grupo São Roque ocorrem na região em pauta, distribuindo-se de preferência ao longo de faixas alongadas, segundo a direção geral $\mathrm{ENE}$, conforme ilustra a figura 2 .

A ordenação dessas unidades se baseou no mapeamento da superficie $S_{0}$ (estratificação reliquiar), que normalmente se dispõe paralelamente à foliação $S_{1}$, adiante descrita. A figura 3, modificada de Carneiro (1983) e Carneiro et al. (1984), esquematiza a coluna litoestratigráfica admitida. As relaçōes entre unidades podem ser visualizadas nas seções geológicas da figura 2.

As espessuras que constam desta ilustração foram estimadas com base em perfis geológicos e dados de sondagem realizados nos horizontes carbonáticos das pedreiras situadas a sul de Cajamar. A Pedreira Cinco, também conhecida como Pires (Foto 2 e Fig. 4) constitui a mais extensa e completa exposição dessas rochas. Nela se pode estimar, sem aparentes repetiçóes tectônicas, uma espessura da ordem de uma centena de metros para o "pacote" carbonático. Para as demais unidades litoestratigráficas presentes, as aproximações sobre espessuras são ainda precárias.

De modo generalizado, pode-se dizer que ocorrem na base da coluna metassedimentos detríticos, predominantemente metapelíticos, representados por xistos de diferentes tipos petrográficos que passam transicionalmente, com o decréscimo do grau metamórfico, a filitos. Entre os metapelitos se alojam corpos de anfibolitos metabasíticos.
Próximo ao topo dos metapelitos ocorrem calcários $\mathrm{e}$ dolomitos metamórficos. Coroando a coluna, encontra-se um pacote de metapsamitos com intercalações metapelíticas.

Os perfis geológicos levantados, as sondagens realizadas em Jordanésia e a observação da distribuição das rochas carbonáticas ao redor do Granito Tico-Tico (Carneiro op. cit. Dantas et al. 1986) são fortes evidências de que o nível carbonático de Cajamar diminui rapidamente de espessura para norte.

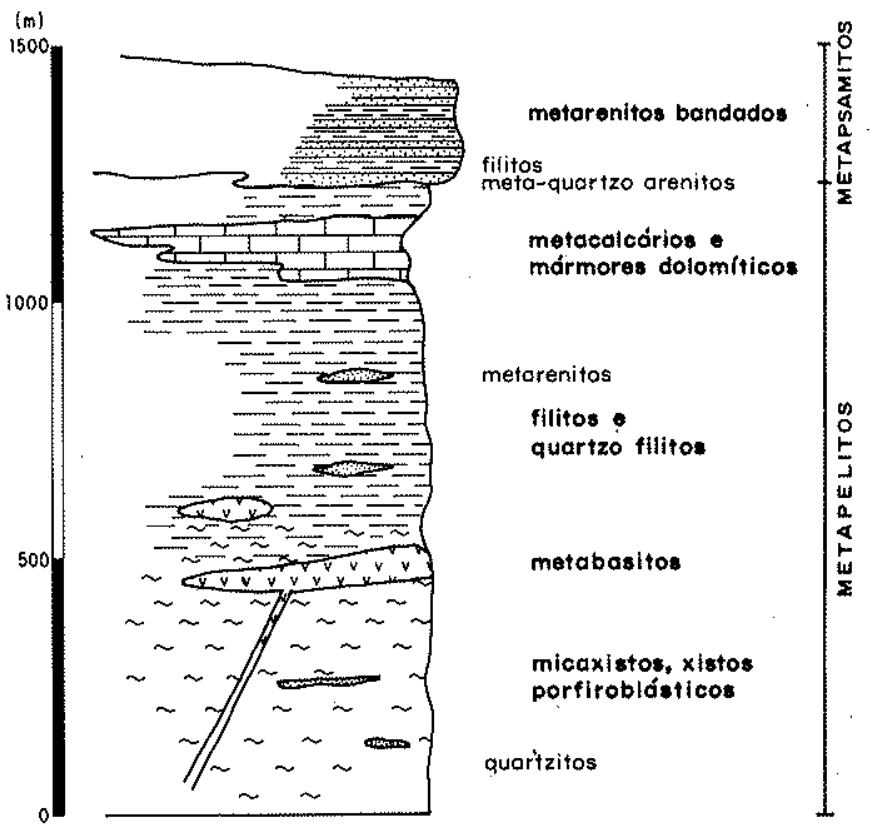

Figura 3 - Coluna litoestratigráfica da região de Cajamar-Jordanésia. A escala vertical, indicativa de espessuras aparentes, foi estimada a partir das seçóes geológicas

$\mathrm{Na}$ região de Jordanésia e mais para leste, em Campo Limpo e Francisco Morato, não há elementos para se suspeitar que este nivel carbonático tenha continuidade. Entretanto, ao redor do Morro do Tico-Tico, e principalmente ao longo
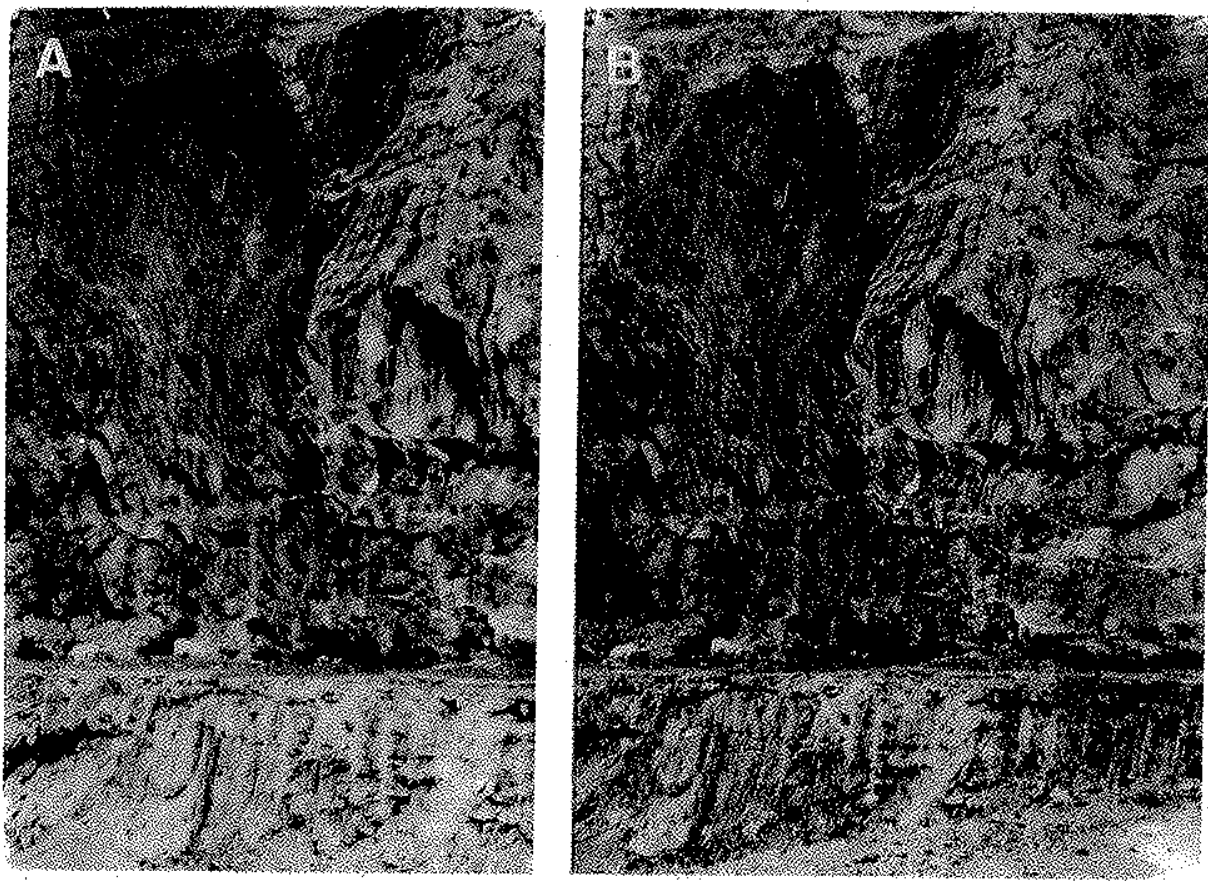

Foto 2 - Montagem de um par esteroscópico utilizado nos trabalhas estruturais. Bancadas da Pedreira Cinco (Pires) 

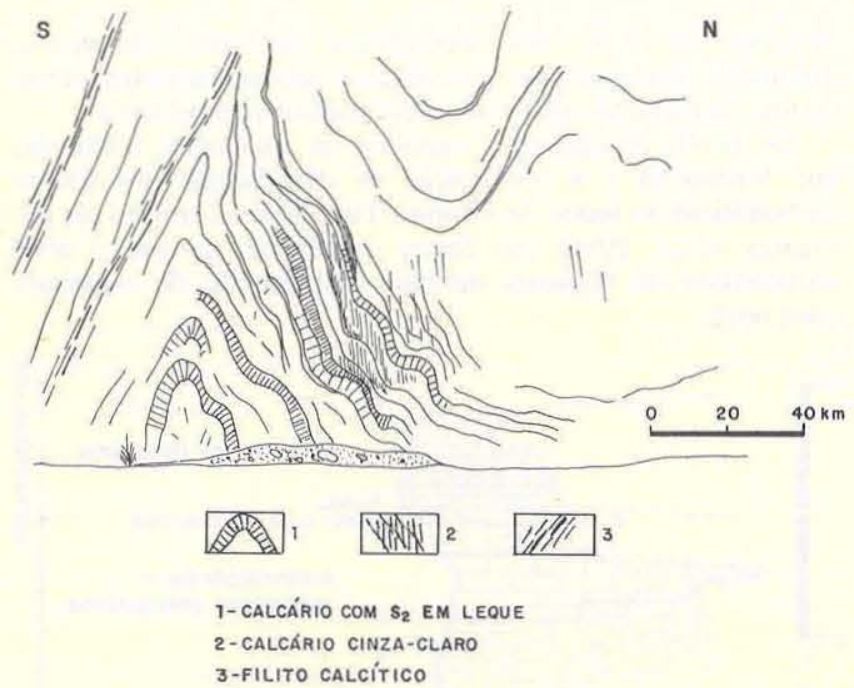

Figura 4 - Estrutura antiformal em rochas carbonáticas da Pedreira Pires mostrando distribuição em leque da clivagem $\mathrm{S}_{2}$

da faixa que se estende a sul deste corpo granítico até Perus, as rochas carbonáticas são mais freqüentes, apresentando composição cálcio-silicatada.

\section{Metapelitos Os metapelitos basais são representados por} duas unidades. A meridional é constituída por uma faixa de micaxistos onde predominam moscovita xistos; a outra são os filitos siricíticos. Com menor freqüência ocorrem estaurolitamoscovita xistos, por vezes porfiroblásticos. As intercalaçöes mais comuns são de metarenitos finos e quartzitos.

Os quartzitos sâo metapsamitos com mais de $80 \%$ de quartzo enquanto os metarenitos, menos puros, são comumente arcosianos, ou mesmo grauváquicos. Por vezes, ao microscópio, é possível discernir nos metarenitos os contornos do quartzo sedimentar no interior de cristais recristalizados deste mineral.

Os filitos sericíticos são os litótipos mais comuns na área estudada, ocorrendo entre eles pequenas intercalaçōes de quartzo filitos. Subordinadamente, afloram metarenitos de granulação fina. São rochas geralmente foliadas ou até mesmo com aspecto laminado. Esta última feição, que também é observada nos micaxistos deve-se à presença de uma clivagem de crenulação plano-axial às dobras de segunda geração, adiante descritas. (Foto 3 ).

$\mathrm{O}$ bandamento composicional nos metapelitos geralmente $\varepsilon$ de ordem milimétrica a centimétrica, sendo ressaltado, na maior parte das vezes, nos afloramentos de rochas alterada, por meio da variação de cores vermelhas, roxas e amarelas.

Observa-se uma variação no grau metamórfico dos metapelitos no flanco sudeste da calha sinclinorial referida mais adiante. De sul para norte ocorrem micaxistos portadores de porfiroblastos de estaurolita parcialmente sericitizados muito bem expostos ao longo do Córrego do Itaim.

A isógrada da sillimanita que contorna o Morro do TicoTico (Caneiro op. cit.) situa-se logo a sul da área pesquisada.

Os micaxistos transicionam para filito ao longo de uma faixa com aproximadamente $200 \mathrm{~m}$. A partir de um certo ponto, os filitos sericíticos passam a predominar.

Anfibolitos metabasíticos Corpos de anfibolitos metabasíticos se alojam entre as unidades metapelíticas acima descritas, principalmente na região próxima ao contato dos micaxistos com os filitos. Quando não alterados, os anfibolitos mostram cores verde-acinzentadas e estrutura normalmente maciça. Sua composição essencial é dada por actinolita, albita, epídoto e clorita.

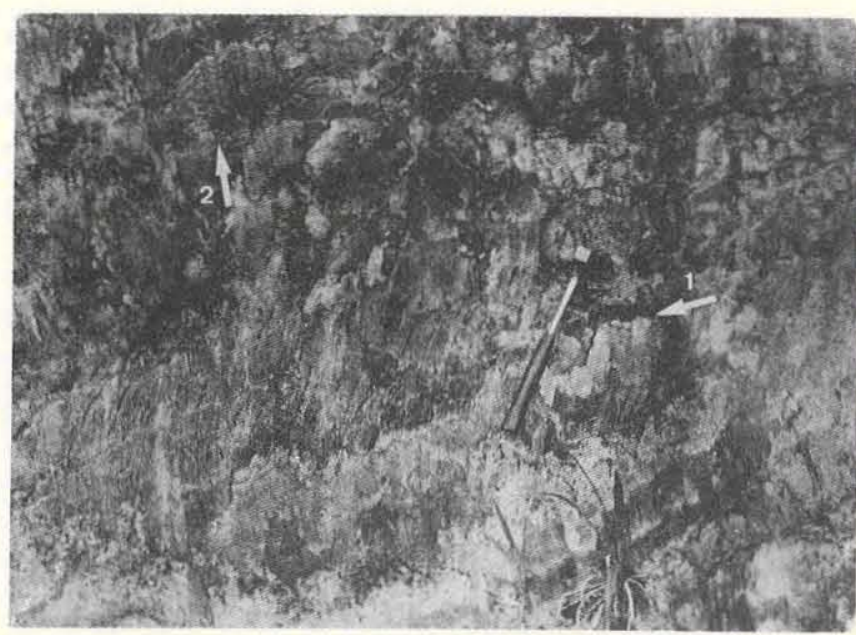

Foto 3 - Filitos com estratificação reliquiar paralela a $S_{f}$ (seta 1) e com proeminente foliaçâo plano-axial $S_{2}$ (seta 2 ), a qual divide os níveis metapelfticos em microlítons e segmentos tabulares de aspecto laminar. Os planos da foliação $S_{2}$ foram suavemente ondulados pela deformação de fase $F_{3}$. Corte da Via Anhanguera situado a norte de Jordanésia

Rochas carbonáticas Próximo ao topo dos metapelitos ocorre um nível de rochas carbonáticas. Trata-se de calcários e dolomitos metamórficos com intercalaçōes muito localizadas de metapelitos, representados por filitos sericíticos ou carbonáticos e metargilitos.

O tipo mais comum de rocha carbonática que ocorre nas pedreiras situadas a sul de Cajamar é um calcário metamórfico bandado, com alternância de níveis centimétricos a decimétricos de coloração ora cinza-claro, ora cinza-escuro, granulação fina e estrutura maciça. Nos calcários pretos ou cinza-escuros ocorre grafita, que, por vezes, se concentra em planos de clivagens disjuntivas. Essas rochas se encontram recortadas por um reticulado de veios, geralmente centimétricos, de calcita e/ou quartzo.

As análises químicas disponíveis e dados da literatura revelam que as rochas carbonáticas da região são calcários metamórficos calcíticos ou dolomíticos. Nas pedreiras Um, Dois, Três, Quatro e Cinco, de propriedade da Fábrica Nacional de Cimento Portland Perus, ocorrem teores inferiores a $4 \%$ de $\mathrm{MgO}$, segundo IPT (1981b). A lente truncada pela Falha do Gato Preto é também de calcário metamórfico com teores baixos em magnésio (Knecht 1950). Nesta lente se desenvolveram as pedreiras Antiga e Gato Preto (a SW da falha).

Nas pedreiras acima referidas ocorrem vários tipos de rochas carbonáticas que são descritos na tabela 1. A área-tipo de ocorrência está na Pedreira Cinco.

Mármores dolomíticos de granulação fina são encontrados na Pedreira do Tombador, situada logo a SW da cidade de Cajamar, e na Pedreira Nova, situada a norte do Morro Agudo. Nesta última pedreira, Knecht (op. cit.) registrou teores de $\mathrm{MgO}$ em torno de $20 \%$. A rocha predominante é um dolomito bandado muito brechado, com níveis geralmente centiméticos de cor cinza-escuro. Localmente, esses nfveis se apresentam bastante fraturados e descontínuos, podendo esta feição representar o resultado do colapso de camadas provocado pela dissolução de níveis evaporíticos intercalados nos dolomitos (Fig. 5).

$\mathrm{Na}$ Pedreira Cinco ocorre de forma restrita uma rocha formada por lama micrítica, que é cortada por clivagens disjuntivas milimétricas, nas quais se orientam cristais de calcita esparítica e quartzo. Sua cor é verde-clara, aflorando em pacotes de espessura decimétrica a métrica.

Rochas carbonáticas não afloram nos bairros de Lavrinhas e Vila Branca, porém sondagens realizadas naquele local 
recuperaram predominantemente rochas carbonáticas muito pouco metamorfizadas, com variedades de cores cinza-claro a médio, estrutura maciça ou localmente brechada. Trata-se de metacalcarenitos constituídos essencialmente de componentes aloquímicos (intraclastos, pelóides e oncólitos) com matriz formada de lama carbonática neomórfica, predominantemente calcítica. Intercalações metapelíticas são raras.

No bairro Vila Branca, que fica situado à margem esquerda do Ribeirão das Lavras, ocorre um metaconglomerado petromítico, dolomítico, por vezes brechado, de cor cinza-claro avermelhado. Os clastos são principalmente de quartzo e fragmentos líticos (quartzito, micríto, agregados de apatita, e siltito). Um outro tipo de metaconglomerado, também ali encontrado, apresenta matriz de sílica microcristalina e extraclastos dolomíticos subangulosos e arredondados. É interessante notar que foi registrada por Knecht (op. cit.) na Pedreira Calcárea, que fica situada pouco mais a oeste da área, a ocorrência de uma rocha com feições conglomeráticas e que até o momento não foi ainda devidamente estudada.

Metarenitos No topo da coluna litoestratigráfica ocorre um pacote de metarenitos e metarenitos bandados, arcosianos, por vezes conglomeráticos, de granulação fina a média, e meta-quartzo arenitos. Entre estes litotipos encontram-se freqüentes intercalações de filitos.

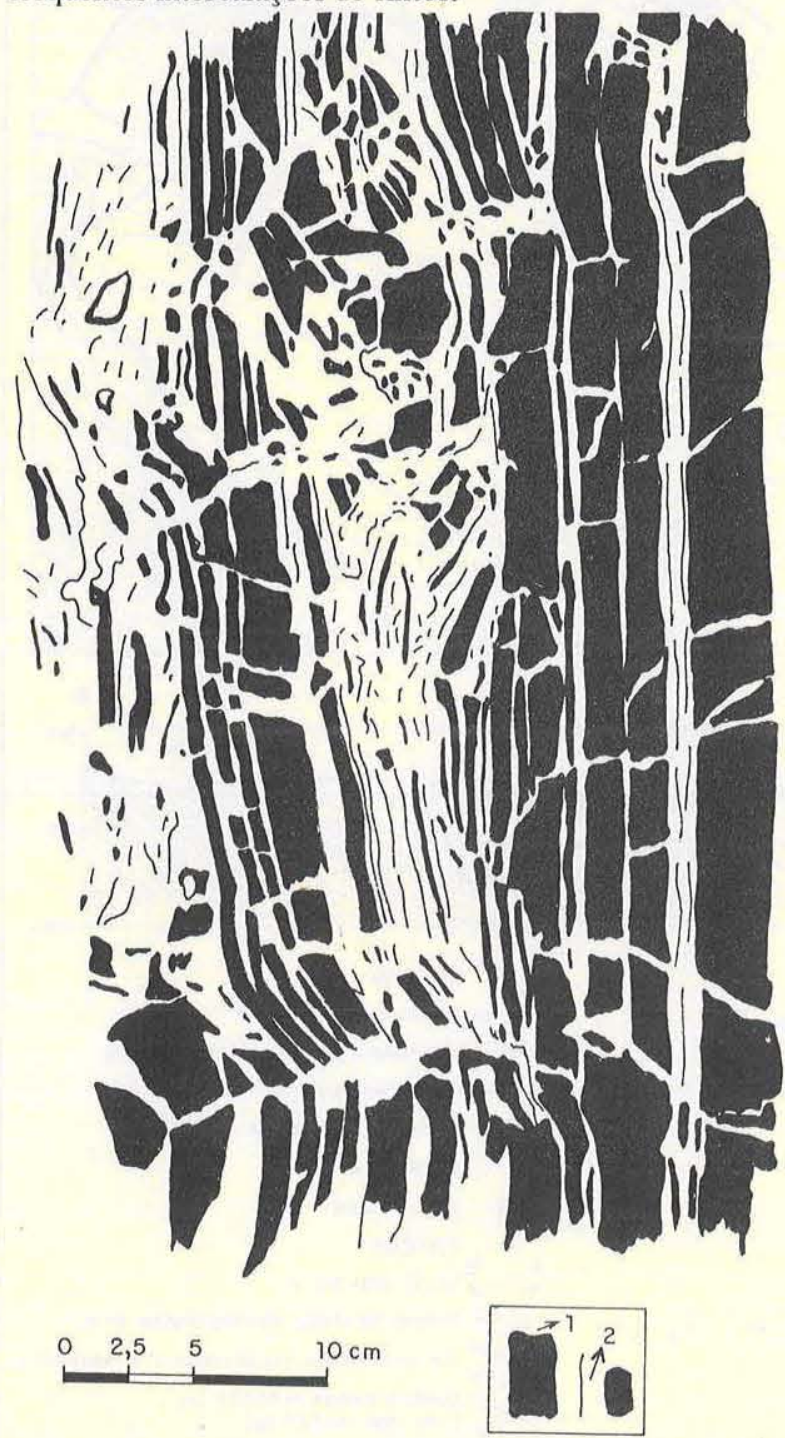

Firgura 5 - Dolomito brechado cortado por veios de calcita. Provável estrutura de colapso. 1. Dolomito cinza-escuro; 2. Dolomito cinza-claro. Representação esquemática de foto obtida na Pedreira Nova
Os pacotes de metarenitos bandados ocorrem em faixas orientadas regionalmente segundo a direção $\mathrm{NE}$, sendo mais expressiva aquela que sustenta as cristas alonadas onde foi assentado o bairro de Vila Branca da cidade de Cajamar. A norte de Jordanésia ocorre a terminação de outra faixa de metarenitos, que se estende mais para NE da área pesquisada (Fig. 2).

Coberturas cenozóicas As coberturas cenozóicas da região são depósitos aluvionares, coluvionares e de tálus. Esses depósitos podem ocorrer de forma isolada ou estar intimamente relacionados entré si. Vinculam-se à evolução geomorfológica da região, que se insere no domínio da Serrania de São Roque (Almeida 1964, Ponçano et al. 1981).

Ao longo dos principais cursos d'água da rede de drenagem (ou formando pequenos alvéolos) ocorrem depósitos aluvionares inconsolidados e mal selecionados de cascalhos, areias e argilas. Localmente, encontram-se também restos de matéria orgânica vegetal dispersos em estratos de areia fina e silte.

Observa-se nas vertentes uma cobertura coluvionar cuja espessura aumenta progressivamente no sentido topo-sopé. Trata-se de material predominantemente argilo-siltoso, de cores avermelhadas, com fragmentos de rocha alterada dispersos nesta matriz fina.

Os bairros Lavrinhas e Vila Branca foram em sua maior parte implantados sobre um depósito com forma alveolar (Fig. 6), o qual é delimitado a SE por elevações sustentadas por metarenitos, metarenitos bandados e filitos. O Ribeirão das Lavras segue seu curso segundo o sentido SE após vencer uma soleira sustentada por aquelas rochas.

O alvéolo de Cajamar é preenchido por materiais interdigitados de natureza coluvionar, aluvionar e de tálus, adiante descritos com maior detalhe.

ESTRUTURAS A observação sistemática das estruturas mesoscópicas, aqui referidas como estruturas menores, permite reconstituir a estrutura local de Cajamar e esboçar a macroestrutura da região.

Estruturas menores As estruturas comuns observadas na área são a estratificação reliquiar, dobras de diferentes gerações, foliações plano-axiais, falhas e juntas. A estratificação reliquiar $\left(\mathrm{S}_{0}\right)$ pode ser identificada nas rochas que afloram em Cajamar-Jordanésia por meio de variações composicionais, formando leitos bastante contínuos milimétricos a centrimétricos. Em particular nos tipos metapelíticos e carbonaticos essas feiçóes são muito comuns. Intercalações regionais de diversos tipos litológicos, onde não há evidências de transposição de estruturas nem discordâncias, também revelam superfícies relacionáveis a $\mathrm{S}_{0}$.

É comum a presença nos metapelitos de uma clivagem ardosiana ou xistosidade $\left(S_{f}\right)$ que, normalmente, ocupa posição paralela aos planos de estratificação reliquiar. As dobras de primeira geração $\left(\mathrm{F}_{1}\right)$, às quais essas foliações estão vinculadas, são fechadas e cerradas ou até mesmo isoclinais. Carneiro (op. cit.) e Carneiro et al. (1985) admitem que estas estruturas foram em grande parte dobras recumbentes, embora assinalem a dificuldade de se estabelecer sua geometria e gênese em virtude da existência de deformações superimpostas.

As dobras da segunda geração $\left(\mathrm{F}_{2}\right)$ afetam a estratificação reliquiar e a clivagem ardosiana ou xistosidade $\left(\mathrm{S}_{1}\right)$. Elas ocorrem com muita freqüência e podem ser observadas em todas as escalas. As rochas carbonáticas e metapelíticas mostram estruturas desta natureza notavelmente bem desenvolvidas (Foto 2 e Fig. 4).

As dobras da fase $\mathrm{F}_{\text {}}$ possuem como foliação plano-axial uma clivagem de crenulação zonal $\left(\mathrm{S}_{2}\right)$ que nos metapelitos pode ser considerada um marcador regional da deformação. Em rochas carbonáticas e nos quartzitos, $\mathrm{S}_{2}$ é uma clivagem 


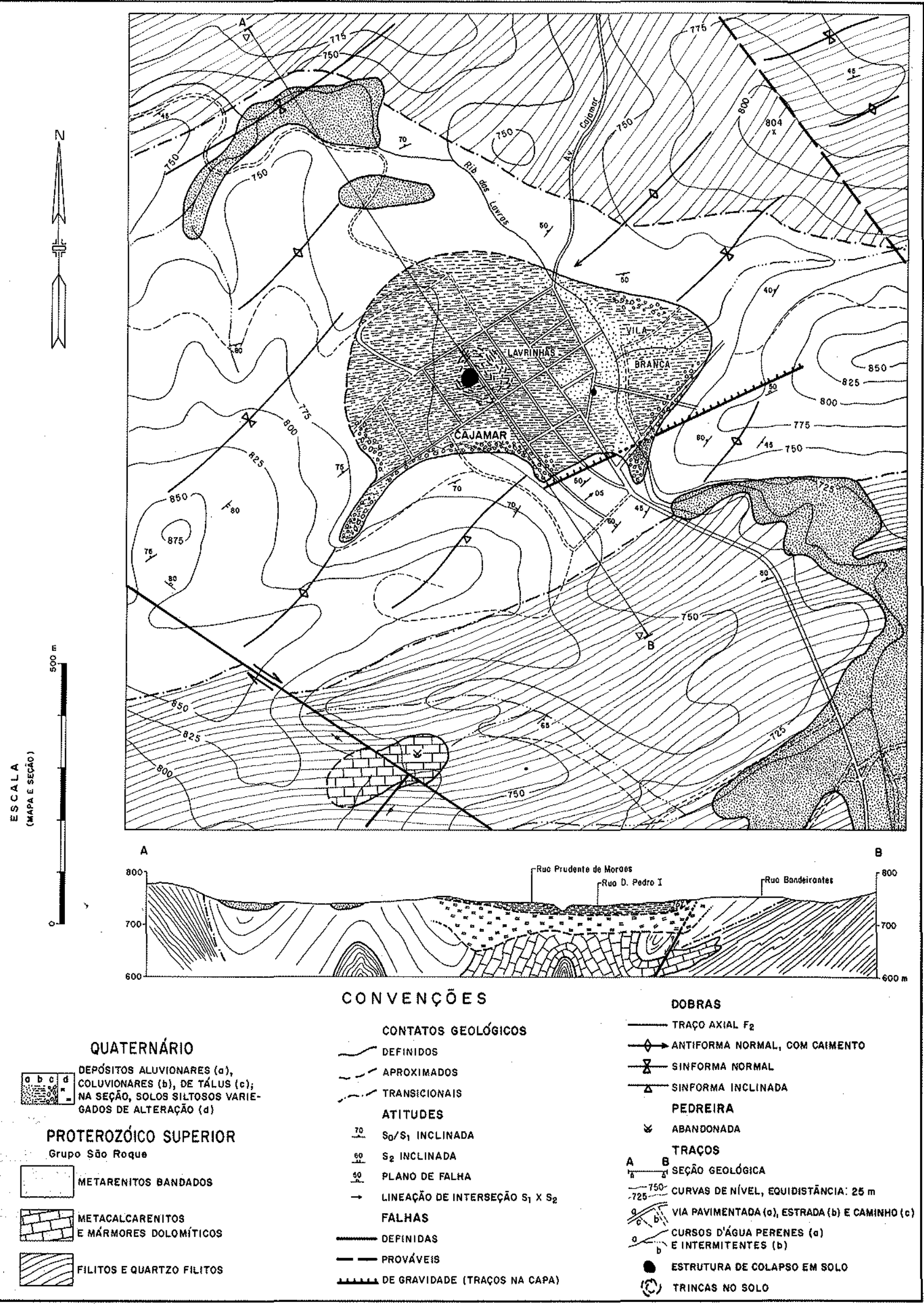

Figura 6-Mapa geológico da cidade de Cajamar (bairros Lavrinhas e Vila Branea) 
Tabela 1 - Feiçôes distintivas das variedades de rochas carbonáticas das pedreiras de Cajamar (modificado de IPT 1981b)

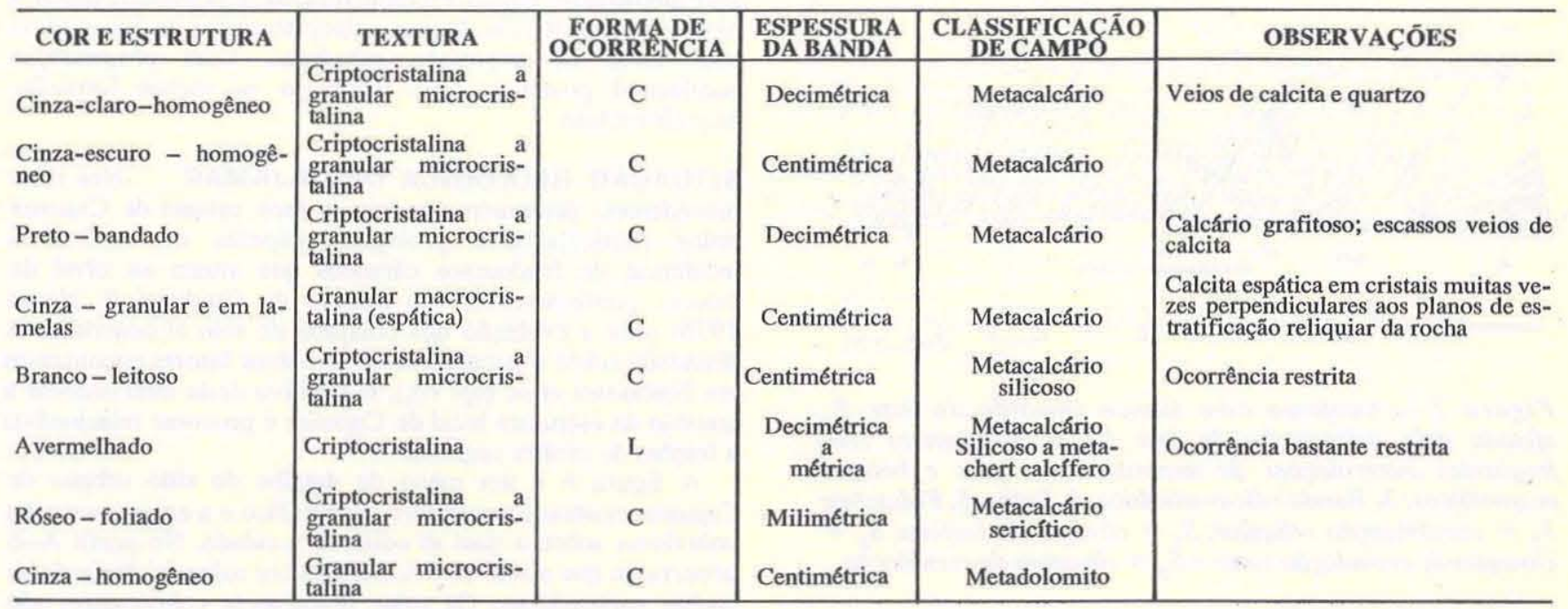

NOTA: Granular macrocristalina: $>0,2 \mathrm{~mm}$; granular microcristalina: 0,01-0,2mm; criptocristalina $<0,01 \mathrm{~mm} . \mathrm{C}=$ camadas; $\mathrm{L}=1 \mathrm{entes}$

disjuntiva disposta na forma de leque ao longo dos flancos das dobras, muitas vezes também exibindo refração ao passar de uma camada carbonática para outra, como pode ser observado na Pedreira Pires (roto 4).

Ao contrário das dobras da fase $\mathrm{F}_{2}$, que ocorrem geraneralizadamente na área estudada, ${ }^{2}$ a fase $\mathrm{F}_{3}$ é representada localmente por ondulações suaves e por uma clivagem de crenulação planọ-axial $\mathrm{S}_{3}$, que trunca as demais foliações metamórficas dos tectonitos (Foto 3 ).

Estruturas maiores As estruturas que podem ser reconhecidas numa escala menor são dobras e falhas; aquelas, reconstituídas a partir de dados de vergência, e estas, em parte por fotointerpretação e observaçōes de campo.

DOBRAS O mapa geológico da figura 2 mostra que na direção $\mathrm{N}-\mathrm{S}$ se repetem dobras com comprimentos de onda da ordem de 500 a $1.000 \mathrm{~m}$. Estas feições variam de ondulaçōes abertas a dobras fechadas e se acham relacionadas ao episódio $\mathrm{F}_{2}$ da deformação.

$\mathrm{Na}$ região norte da área ocorrem filitos com a foliação $\mathrm{S}_{2}$ subverticalizada, num local de fechamento de uma dobră neutra vertical (Fig. 2 e Foto 3), cujo eixo mergulha cerca de $80^{\circ}$ para oeste. Nas proximidades da estrada do Campo Limpo e da Rodovia dos Bandeirantes o eixo desta estrutura

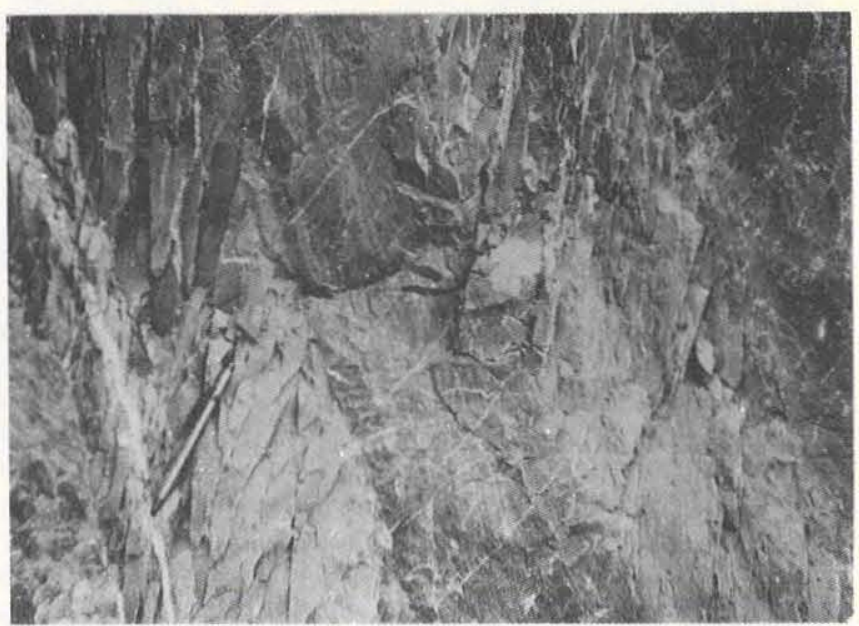

gradualmente se horizontaliza e a dobra neutra passa para a categoria de antiforma. Observa-se, de modo geral, que nas unidades do Grupo São Roque não são raras variações como esta nos padrões de orientação das estruturas da fase $\mathrm{F}_{2}$.

$\mathrm{Na}$ porção central da área ocorre o núcleo de um sinclinório truncado por falhamentos NW. No núcleo desta estrutura ocorrem rochas metapsamíticas e carbonáticas. $\mathrm{O}$ perfil A-B da figura 2 mostra que no flanco SE do sinclinório ocorre um nível de rochas carbonáticas formando dobras fechadas de comprimento de onda hectométrico. Este nível mergulha sob o pacote de metapsamitos que constitui extensa faixa alongada na qual se instalou a depressão alveolar de Cajamar.

Ocorre no domínio dos micaxistos, nas aproximidades do Córrego Itaim (perfil C-D, Fig. 2), uma antiforma com flanco invertido. A figura 7, obtida no mapeamento de um corte da Rodovia Anhangüera situado entre a saída de Cajamar e o referido córrego, mostra com detalhe esta estrutura, onde pode ser vista a relação entre a foliação $S_{2}$ e as superfícies dobradas, dobras menores da fase $\mathrm{F}_{2} \mathrm{e}^{2}$ a deformação correspondente à fase $\mathrm{F}_{3}$.

Pode-se dizer, portanto, que na região estudada a macroestrutura esta vinculada à fase $\mathrm{F}_{2}$ de deformação e as dobras se dispõem segundo direções NE ou E-W. No geral, predominam dobras desta fase do tipo normal com caimento,

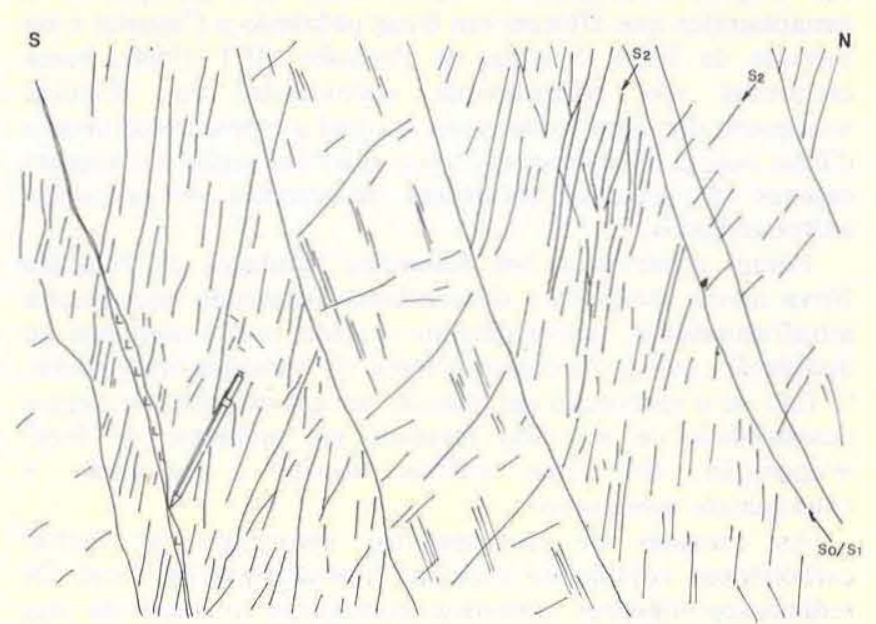

Foto 4 - Refração da Clivagem disjuntiva $S_{2}$ no contato entre leitos carbonáticos (dois primeiros tipos descritos na tabela 1 ). Ao lado, representação esquemática da foto 


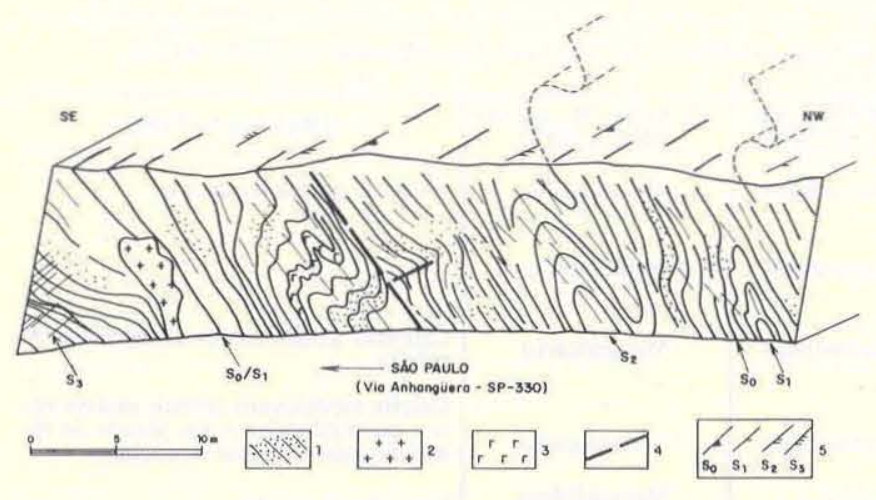

Figura 7 - Antifoma com flanco invetido da fase $F_{2}$ afetada pela deformação da fase $F_{3}$. 1. Metarenitos com freqüentes intercalações de micaxistos; 2. Veios e bolsões pegmattiticos; 3. Banda cálcio-silicática; 4. Falha; 5. Foliaçôes: $S_{0}=$ estratificação reliquiar, $S_{1}=$ clivagem ardosiana, $S_{2}=$ clivagem de crenulação zonal e $S_{3}=$ clivagem de crenulação

segundo a terminologia de Rickard (1971) e Ragan (1973). Sẫo reconhecidas ainda dobras inclinadas com caimento, dobras neutras e dobras com flanco invetido.

FALHAS Pequenas falhas truncam, com freqüência, as rochas do Grupo São Roque. Contudo, é reduzido o número de falhas de maior porte representadas nos mapas geologicos disponíveis. No decorrer deste trabalho foram identificadas pequenas falhas de rejeito direcional na Pedreira do Tombador, segundo dois sistemas com orientações NW e NE. A Falha do Gato Preto (Fig. 2), de caráter transcorrente dextral, trunca o segmento oriental das rochas carbonáticas que afloram na área, afetando até a lente sobre a qual se desenvolveram as pedreiras Gato Petro e Antiga.

Falhas com rejeito inclinado mergulhando para NW ocorrem no bairro de Vila Branca e na Pedreira Dois, situada a sul de Cajamar. Nesta pedreira foram observadas falhas normais com igual orientaçấo.

\section{AMBIENTES DE SEDIMENTAÇÃo A organização} das unidades litoestratigráficas da área permite levantar hipótese da existência de um paleoambiente plataformal de águas rasas. Primeiramente teria ocorrido uma deposição de argilitos e siltitos, recobertos por rochas carbonáticas e arenitos.

Estruturas primárias reliquiares, tais como estratificação rítmica gradacional, estratificação cruzada e marcas de onda, são feições sedimentares identificadas em metapelitos e metapsamitos que afloram em áreas próximas a Cajamar e no restante da Folha Santana de Parnaíba (IPT 1984). Essas estruturas são normalmente encontradas em abientes subaquoso de plataformas rasas, no qual a espessura da lâmina d'água coloca os sedimentos sob a ação das ondas e correntes capazes de registrar estruturas decorrentes de processos hidrodinâmicos.

Foram observados nos dolomitos bandados da Pedreira Nova níveis rompidos e descontínuos formando uma brecha intraformacional, provavelmente gerada por fenômenos de dissolução, que provocaram colapso de camadas nesta rocha. $\mathrm{O}$ fato de o carbonato em questấo ser um dolomito reforça a possibilidade de ter sido formado em ambiente de forte evaporação, em zona vadosa, sujeita à exposição e conseqüente ressecação.

As camadas de metapsamitos sotopostas às rochas carbonáticas completam a coluna litoestratigráfica local. Os sedimentos clásticos arenosos constituem o topo de um seqüência granocrescente de uma sedimentação regressiva, sugerindo uma deposição sedimentar com influência continental.
O estudo das feiçōes sedimentares merece um aprofundamento maior. Preliminarmente, é possível levantar a hipótese da existência de uma paleoplataforma de águas rasas com áreas de exposição subaéreas. Uma progradação continental posterior teria recoberto as rochas formadas naquele estágio.

SITUAÇÃo GEOLÓGICA DE CAJAMAR Nos itens precedentes, demonstrou-se que a área urbana de Cajamar reúne particularidade geológicas capazes de explicar a incidência de fenômenos cársticos que atuam ao nível de fatores predisponentes (no sentido de Guidicini \& Nieble 1976) para a evolução dos colapsos de solo aí ocorridos. A discussão sobre o papel desses e de outros fatores encontra-se em Nakasawa et al. (op. cit.). É objetivo deste item enfocar a questão da estrutura local de Cajamar e procurar relacioná-la a feiçőes de caráter regional.

A figura 6 é um mapa de detalhe do sítio urbano de Cajamar mostrando o alvéolo topográfico e a extensa mancha coluvionar sobre a qual se edificou a cidade. No perfil A-B observa-se que o solo coluvionar recobre solos de alteração de rochas carbonáticas. Os solos tipicamente coluvionares são essencialmente argilosos, incorporando blocos e matações no sentido do sopé das encostas, formam-se, assim, corpos de tálus. Principalmente junto ao Ribeirão das Lavras, os solos aluvionares se interdigitam-se no coluvião. Este depósito de natureza coluvionar, aluvionar e de tálus possui espessuras da ordem de $20 \mathrm{~m}$ (IPT 1987).

Abaixo do depósito acima descrito ocorrem solos siltosos provenientes principalmente da alteração de filitos. Por vezes observa-se certa estruturação nestes solos. Fragmentos milimétricos a decimétricos de metarenitos, quartzo e filitos são comumente encontrados.

Nas proximidades do topo rochoso, que pode estar até a aproximadamente $100 \mathrm{~m}$ abaixo da superfície, as sondagens recuperam solos inconsistentes, marrom-escuros e com cavidades preenchidas ou nåo por água. Tais solos foram interpretados como materiais residuais da alteração de rochas carbonáticas. As dimensōes das cavidades oscilam entre $1 \mathrm{e}$ $6 \mathrm{~m}$ na vertical, e as extensões horizontais são de até $15 \mathrm{~m}$.

As rochas carbonáticas amostradas em subsuperfície são geralmente maciças, de cor cinza, fraturadas, muitas vezes exibindo alargamento das descontinuidades por fenômemos de dissolução. Cavidades preenchidas por solo, ou apenas água, foram também encontradas.

A organizaçẩo estrutural da área revela que o padrão regional de sucessão de antiformas e sinformas, normais ou inclinadas, repete-se no bairro de Lavrinhas. O perfil A-B da figura 6 mostra a presença de rochas carbonáticas compondo uma ampla antiforma. No conjunto de fatores que condicionam o evento cárstico, esse arranjo particular exerceu influência expressiva.

CONCLUSÕES A partir da identificação dos padrões regionais de dobramentos, da orientação da estratificação reliquiar $\mathrm{S}_{0}$ (frequentemente paralela a foliação $\mathrm{S}_{1}$ ) e das foliaçōes $\mathrm{S}_{2}^{0}$ e $\mathrm{S}_{3}$ presentes nos metapelitos, foi determinada uma coluna estrátigráfica esquemática para a região, na qual se destacam dois pacotes. O pacote basal é predominantemente metapelítico; o outro, de topo, tem natureza metapsamítica. Nas aproximidades do topo do pacote metapelítico ocorre um nível de rochas carbonáticas aproximadamente contínuo, que se expőe a sul da cidade de Cajamar e do Morro do Rosário. As observaçőes locais e regionais mostram que o nível de rochas carbonáticas de Cajamar diminui rapidamente de espessura para norte.

O grau metamórfico diminui no sentido da base para o topo da coluna. Na base ocorrem micaxistos com estaurolita, com paragênese compatível ao grau médio (Winkler 1977). Os micaxistos transicionam para filitos de grau baixo a muito baixo. 
O traço marcante da estrutura geológica da regiáo de Cajamar-Jordanésia é a sucessão de dobras vinculadas ao episódio de deformação $\mathrm{F}_{2}$, descrito na região por Carneiro (op. cit.). As estruturas $\mathrm{F}_{2}$ incluem amplas e longas sinformas e antiformas, com planos axiais de direções ENE, e mergulhos subverticais. Predominam eixos e charneiras com mergulhos sub-horizontais. Entretanto, a norte de Jordanésia, foi mapeada uma dobra neutra vertical dessa mesma fase $\mathrm{F}_{2}$. As lentes de rochas carbonáticas normalmente afloram em núcleos antiformais, sendo também este o caso daquela que ocorrem em subsuperfície na cidade de Cajamar.

O paleoambiente no qual se desenvolveu a sedimentação da área foi possivelmente de uma plataforma de águas rasas sobre a qual progradou uma sedimentação continental psamo-pelítica. Algumas áreas de exposição subaérea devem ter existido durante a deposição carbonática, que foi a seguir interrompida pelo avanço de uma sedimentação continental.

Agradecimentos Os autores agradecem a colaboração do Geol. Mário Tadao Sakate durante o desenvolvimento dos trabalhos de campo e nas discussões iniciais; à desenhista Mirna M. Ferracini e ao fotógrafo Álvaro Camargo Kopezinsky, pela qualidade das ilustrações, e ao Instituto de Pesquisas Tecnológicas do Estado de São Paulo S.A. (IPT), pelo apoio prestado à elaboração deste artigo.

\section{REFERÊNCIAS BIBLIOGRÁFICAS}

ALMEIDA, F.F.M. de. 1964. Fundamentos geológicos do relevo paulista Bol. IGG, Săo Paulo (41): 169-263.

CARNEIRO, C.D.R. 1983. Análise estrutural do Grupo São Roque na faixa entre o Pico do Jaragúa e a Serra dos Cristais, SP. São Paulo. $155 \mathrm{p}$. (Tese de Doutoramento, Inst. Geoc. USP).

CARNEIRO, C.D.R.; HASUI, Y.; DANTAS, A.S.L. 1984. Contribuição ao estudo da litoestratigrafia do Grupo São Roque na faixa Jaraguá-Cristais, SP. In: CONGR. BRAS. GEOL., 33, Rio de Janeiro, 1984, Anais... Rio de Janeiro, SBG, v. 7, p. 3212-3226.

CARNEIRO, C.D.R.; HASUI, Y.; NAGATA, N.; LIMA, M.O. 1985. Padrōes de superposição de estruturas do Grupo Săo Roque na faixa Jaraguá-Cristais (SP). Rev. Bras. Geoc. 15(2):116-130.

DANTAS, A.S.L.; ALMEIDA, M.A.; TEIXEIRA, A.L.; NAGATA, N.; BISTRICHI, C.A, 1986, Integração geologica das Folhas Santana de Parnaíba e Guarulhos. In: JORNADA CARTA GEOL. ESTADO SĀO PAULO EM 1:50.000, 2, São Paulo, 1986, Atas... São Paulo, SICCT/Prominério (no prelo).

GUIDICINI, G. \& NIEBLE, C.M. 1976. Estabilidade de taludes naturais e de escavação. Săo Paulo, Blücher/Edusp. 170 p.

INSTITUTO DE PESQUISAS TECNOLÓGICAS DO ESTADO DE SÄO PAULO S.A.-IPT. 1981a. Caracterização geológicoestrutural em pedreiras de calcário da Cia. Nacional de Cimento Portland Perus, Cajamar - SP, São Paulo, IPT. 19p. (Relatório 15.814)

INSTITUTO DE PESQUISAS TECNOLÓGICAS DO ESTADO DE SAO PAULO S.A.-IPT. 1981b. Caracterização geologicoestrutural e reavaliaço das reservas das jazidas de calcário da Cia. Nacional de Cimento Perus. Cajamar - SP, São Paulo, IPT 4v. (Relatório 17.180)
INSTITUTO DE PESQUISAS TECNOLÓGICAS DO ESTADO DE SÄO PAULO S.A.-IPT. 1984. Geologia da Folha de Santana de Parnåba. SP. São Paulo, IPT. 1v. (Relatório 20.767)

INSTITUTO DE PESQUISÁS TECNOLOGICAS DO ESTADO DE SĀO PAULO S.A.-IPT. 1987. Diagnóstico do abatimento do terreno em Cajamar - SP e definição de modelos e diretrizes para a resoluçáo do problema. São Paulo, IPT. 7 v. (Relatório 25.053)

KNECHT, T. 1950. Ocorrências minerais do Estado de São Paulo, São Paulo, Bol. IGG, 144 p.

NAKAZAWA, V.A.; PRANDINI, F.L.; ÁVILA, I.G.; PONÇANO, W.L.; BRAGA, A.C. de O.; BOTTURA, J.A.; SANTORO, E. 1987. Cajamar-Carst e Urbanização: Investigação e Monitoramento. In: CONGR. BRAS. GEOL. ENG., 5, São Paulo, 1987. Anais... São Paulo, ABGE. v.2, p.443-460.

PONÇANO, W.L.; CARNEIRO, C.D.R.; BISTRICHI, C.A.; ALMEIDA, F.F.M. de; PRANDINI, F.L. 1981. Mapa Geomorfologico do Estado de São Paulo. São Paulo, IPT. 94 p. (Monografias 5)

RAGAN D.M. 1973. Structural Geology. An introduction to geometrical techniques. 2ed. New York, Wiley. 208 p.

RICKARD, M.J. 1971. A classification diagram for fold orientation Geol. Mag., 108(1):23-26.

WINKLER, H.G.P. 1977. Petrogênese das rochas metamórficas (Trad. Carlos Burges Jr.). Porto Alegre, Blücher/Co-ediçőes UFRGS.

MANUSCRITO 527

Recebido em 18 de Marco de 1988 Revisảo aceita em 15 de Junho de 1988

\section{ALGUMAS REGRAS PARA A PREPARAÇÃO DE TABELAS}

Chamamos a atenção dos autores de manuscritos a serem enviados à RBG que, segundo a ABNT PB-279, as casas das tabelas não devem ficar em branco. Quando não houver valor ou dado para o seu preenchimento, adotam-se os seguintes sinais:

a) - (traço) quando o valor do dado for nulo;

b) 0 (zero), 0,0 (zero vírgula zero) quando o valor numérico do dado for menor do que a metade da unidade ou fração da unidade adotada para a expressão do dado;

c) ... (três pontos) quando não se dispuser do dado;

d) chamadas para outros casos.

Os editores 